NBSIR 86-3455

\title{
Investigation of the Use of Nondestructive Methods for Inspection of Seams of Single-Ply Roofing Membranes
}

Walter J. Rossiter, Jr.

U.S. DEPARTMENT OF COMMERCE National Bureau of Standards National Engineering Laboratory Center for Building Technology Gaithersburg, MD 20899

September 1986

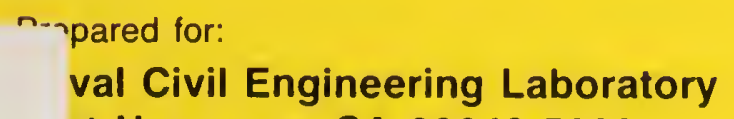



NBSIR 86-3455

\section{INVESTIGATION OF THE USE OF NONDESTRUCTIVE METHODS FOR INSPECTION OF SEAMS OF SINGLE-PLY ROOFING MEMBRANES}

Walter J. Rossiter, Jr.

U.S. DEPARTMENT OF COMMERCE National Bureau of Standards National Engineering Laboratory Center for Building Technology Gaithersburg, MD 20899

September 1986

Prepared for:

Naval Civil Engineering Laboratory

Port Hueneme, CA 93043-5003

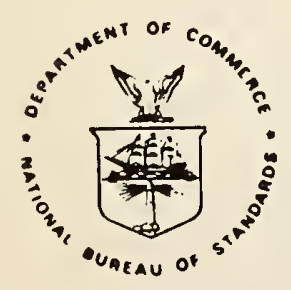

U.S. DEPARTMENT OF COMMERCE, Malcolm Baldrige, Secretary NATIONAL BUREAU OF STANDARDS, Ernest Ambler, Director 



\section{ABSTRACT}

Investigations were conducted regarding the use of the ultrasonic pulse echo and the infrared thermography nondestructive evaluation (NDE) methods for detecting voids and delaminations in adhesivebonded seams of single-ply roofing membranes. Previous studies had indicated that these defects could be detected using the two NDE methods. In the present study, voids incorporated in $1.2 \mathrm{~m}$ (48 in.) long seam test specimens were located by the pulse-echo method using a wheel transducer to scan along the length of the seam. These results indicated that the ultrasonic pulse echo method using a wheel transducer can be useful as a field technique for assisting in the quality assessment of seams.

When using the infrared thermography method to evaluate the seam specimens, it was found that, unlike previous studies, only sections of some voids were detected and that other voids were not detected at all. It was suggested that collapse of the voids due to the applied pressure during seam formation might have provided insufficient surface temperature differential between the bonded areas of the seam and the void areas of the seams during transient heat flow. The results raised concerns that the infrared thermography method may not be practical for the general detection of voids of seams in service.

Key words: adhesive bonds; detection; infrared thermography; membranes; nondestructive evaluation; roofing; seams; single-ply; ultrasonic pulse echo; voids. 
Page

ABSTRACT . . . . . . . . . . . . . . . . . 1 . . $1 \mathfrak{i}$

1. INTRODUCTION . . . . . . . . . . . . . . . 1

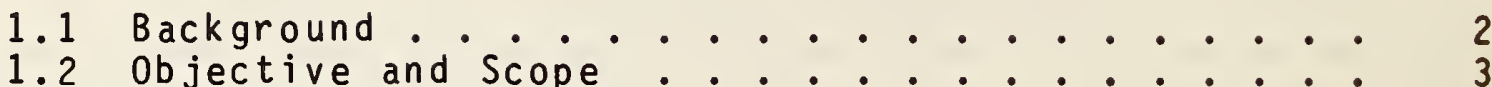

2. EXPERIMENTAL . . . . . . . . . . . . . . 5

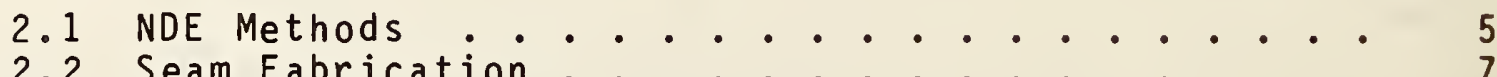

2.2 Seam Fabrication . . . . . . . . . . 7

3. RESULTS AND DISCUSSION . . . . . . . . . . . 10

3.1 Large-Sized Membrane Specimens . . . . . . . 10

3.2 Small-Sized Membrane Specimens . . . . . . . 16

4. SUMMARY AND RECOMMENDATIONS .............. 18

5. ACKNOWLEDGEMENTS ..................... 21

6. REFERENCES . . . . . . . . . . . . 22 


\section{LIST OF TABLES}

Page

Table 1. Membrane Materials Included in the Study . . . . 24

Table 2. Results of NDE Inspections of Large-Sized Membrane Specimens........... . 25

Table 3. Results of NDE Inspections of Small-Sized Membrane Specimens........... 26

\section{LIST OF FIGURES}

Figure 1. Diagram of the $1.2 \mathrm{~m}$ ( $48 \mathrm{in.)}$ Large-Sized

Figure 2. Plan of the Chamber Test Specimen . . . . . . 28

Figure 3. Types of Voids in Lap Seams . . . . . . . . 29 



\section{INTRODUCTION}

Durable, single-ply roofing membranes are characterized, among other factors, as having seams that remain watertight over the intended service life of the roofing. Failure of a seam can result in water penetration of the roofing system causing damage to itself, other building components, and building contents, and also loss of thermal efficiency of the roof insulation. In spite of the importance of having long-lasting, watertight seams, the quality of those fabricated in the field is usually only assessed at the time of roofing construction by visual observation, and by manual inspection of the lap edge to ascertain that the seam is bonded at that location.

Nondestructive evaluation (NDE) procedures are not presently available to assure that bond formation is complete in all sections of the seam. The development of NDE methods would be beneficial for a number of reasons. They have the potential of providing a quality control technique for examining the completeness of adhesive application and the resultant bond formation during the formation of seams in the field. In addition, NDE methods could be used to investigate the extent of disbonding, if such a problem were to arise during service. Also, such methods could assist in obtaining knowledge on adhesive-bond performance. For example, environmental conditions leading to loss of adhesivebonds during service, or growth of voids within seams could be investigated without destruction of the seams. 


\subsection{Background}

The use of NDE methods for detecting voids and delaminations in adhesive-bonded seams of single-ply roofing membranes has been under preliminary investigation at the U.S. National Bureau of Standards (NBS) [1,2]. Voids may be incorporated in seams at the time of fabrication due to lack of total adhesive coverage on sections of the sheets to be bonded. Delaminations may occur through disbonding after seam fabrication. The previous NBS studies have reported on the potential for using the ultrasonic pulse echo method and the infrared thermography method as a means of detecting the presence of the defects in the interior portions of the seams where visual inspection is impossible. Factors that may affect instrument response, such as pressure applied during seam fabrication, void size, water in the void, and type of substrate under the seam, have been investigated [2]. Both the ultrasonic pulse echo and the infrared thermography methods have had considerable application to the detection of defects in building components, composites, and seams of membranes [3-11].

The results of the previous NBS studies [1,2] indicated that, under laboratory conditions, both NDE methods were successful in locating the presence of hidden voids in seam specimens. Nevertheless, it was also found that, as conducted in the laboratory, each NDE technique had certain limitations that could adversely affect its practical use in the field in locating voids and delaminations in seams. In particular, the ultrasonic 
pulse echo method could not detect voids filled with water, and produced false indicators that were dependent on the pressure applied to the transducer during testing. The ultrasonic pulse echo method, as used in the laboratory in the preliminary studies, was considered impractical to use in field applications for scanning large expanses of seams due to the small size (about $19 \mathrm{~mm}$ or $0.75 \mathrm{in}$. diameter) of the transducer. The infrared thermography method had limitations dealing with uniform, controlled heating of the sections of seams using a laboratory hot air blower, and the practicality of using the hot air blower in the field on large expanses of seams under variable environmental conditions.

\section{2 objective and Scope}

This paper presents further results of studies to investigate the feasibility of using the NDE techniques for detecting voids and delaminations in seams of single-ply membranes. The objective was to explore improvements in the NDE techniques that could result in increased potential for their use in the field. In the case of the ultrasonic puise echo method, the principal factor investigated was the use of a wheel transducer that could scan long expanses of seams quickly and at constant pressure. In the case of the infrared thermography method, the primary factor investigated was the potential use of sunlight (absorbed solar radiation) as the source of transient heat flow in the seam. 
Since the previous NBS studies [1,2] were limited to seams fabricated from black EPDM (ethylene propylene diane terpolymer) rubber, the use of the NDE methods for detecting voids incorporated in seams of other single-ply membrane materials was explored. The ultrasonic pulse echo and the infrared thermography methods are, in principal, applicable to seams of elastomeric, thermoplastic, and polymer-modified bitumen [1,2]. However, laboratory tests have not been conducted on all these types of single-ply membrane materials. The additional materials investigated in the present study were white EPDM, white chlorosulfonated polyethylene (CSME), and styrene-butadiene-styrene (SBS) modified bitumen.

4 


\section{EXPERIMENTAL}

\subsection{NDE Methods}

A description of the ultrasonic pulse echo and infrared thermography methods used in the study has been given previously [1,2]. Only a brief summary of the methods is given here.

\subsubsection{The Ultrasonic Pulse Echo Method}

In this method, ultrasonic waves are transmitted into the test specimen (e.g., single-ply membrane seam) and are reflected off discontinuities and at interfaces. The time required for the reflected signal (echo) to be detected is dependent on the distance it travels and the speed of the pulse in the test material. An echo associated with a completely bonded seam would pass through two membrane layers. If the area of the seam under inspection contained a void, the echo would pass through one layer of membrane. Thus, twice as much time is required for the echo to pass through a completely bonded seam than through the unbonded (void) area.

Two piezoelectric transducers of different frequencies were included in the present study, depending on the test specimen being inspected. In the case of large-sized (see section 2.2.1) specimens having 6 voids, a wheel transducer operating at 2.25 MHz was selected. The ultrasonic beam was generated normal to the surface of the test specimen and effectively scanned an area $25 \mathrm{~mm}$ ( 1 in.) in diameter. For the small-sized specimens 
(see section 2.2.2) having two voids, a hand-held transducer with a frequency of $1.0 \mathrm{MHz}$ was used. Water was usually the coupling medium between the specimen surface and both transducers, although in some tests, a petroleum-based lubricating oil was used.

The wheel transducer was mounted on a rolling platform having three wheels. In this manner, the entire length of a test specimen could be inspected by pushing the platform holding the transducer along the specimen surface. The mass of the wheel transducer and platform was about $4.8 \mathrm{~kg}$ (10.6 1bm).

\subsubsection{The Infrared Thermography Method}

If transient heat flow occurs in a material (e.g., a seam in a membrane), the presence of voids or delaminations in it may cause the surface temperature directly above the defect to be at a different temperature than that of a defect-free region. Measurement of the temperature differential using the infrared camera can be used to detect the presence of the defect. The infrared camera used in the present study could detect surface temperature differentials of $0.2^{\circ} \mathrm{C}\left(0.4{ }^{\circ} \mathrm{F}\right)$.

Transient heat flow was normally induced in the seam by heating its surface with a laboratory hot air blower. In some tests (see section 3.2.1), heat lamps were used to heat the membrane 
specimen which was then allowed to cool under ambient conditions or by blowing unheated laboratory air across its surface.

\subsection{Seam Fabrication}

Seams were fabricated from sheets of the single-ply membrane materials (nos. 1-4) listed in table 1. In the case of the nonbituminous specimens (nos. 1-3), the sheets were cleaned with solvents as recommended by the material manufacturers and contact adhesives were applied in accordance with the manufacturers' instructions. The cleaning solvent for the black EPDM was a proprietary product provided by the manufacturer. The seam of the SBS-modified bitumen (no. 4) was prepared using hot asphalt as the adhesive.

Voids of known size were incorporated in the seams by placing masking tape having the desired shape and area on both membrane material surfaces prior to application of the adhesive. The masking tape was removed prior to joining the membrane sheets together for seam formation.

2.2.1 Large-Sized Membrane Specimens

Large-sized membrane specimens having $76 \mathrm{~mm}$ ( 3 in.) wide seams were fabricated from the black EPDM rubber. The length of the specimens was $1.2 \mathrm{~m}$ ( $48 \mathrm{in}$. ) and the width was a minimum of $0.3 \mathrm{~m}$ (12 in.). Six (6) voids of different size and shape were 
incorporated in the seams, as shown in Figure 1. In the fabrication of the large-sized specimens, pressure was applied to the newly-formed seams using a hand roller typical of those employed in the field. The pressure exerted in the process has been measured to be, on the average, $0.7 \mathrm{MPa}\left(100 \mathrm{lbf} / \mathrm{in}^{2}\right)$ [2].

Two types of large-sized membrane specimens were fabricated. For the first type, the specimen consisted only of the rubber sheet with the fabricated seam; that is, the membrane was not mounted on or adhered to any substrate. This specimen could then be placed on any desired substrate during the NDE measurements. This specimen is referred to as the "seam alone" specimen in the present report.

For the second type of large-sized specimen, the seams having voids were included in a $1.2 \times 1.2 \mathrm{~m}(48 \times 48 \mathrm{in}$.) roofing system specimen consisting of membrane, insulation, and deck, as described in Figure 2. The insulation boards were mechanically fastened to the wooden deck, and the EPDM membrane was totally adhered to the fiberboard insulation layer. As evident from Figure 2, the roof system specimen had three seams that were spaced equidistantly across the surface, and that were located above joints in insulation boards. However, for the present study, only one of the three seams was used for the NDE detection of voids. This specimen was constructed in a chamber having a bank of heat lamps mounted above the membrane to enable heating 
of the specimen surface. This specimen is referred to as the "chamber specimen" in the present report.

\subsubsection{Small-Sized Membrane Specimens}

With the exception of the black EPDM (no. 1), the small-sized specimens were approximately $270 \times 200 \mathrm{~mm}(10.5 \times 7.8 \mathrm{in.})$ and contained a $76 \mathrm{~mm}$ ( 3 in.) lap seam centered parallel to the long dimension. The seams of each of these specimens contained two voids that were $44 \mathrm{~mm}(1.8 \mathrm{in.})$ in diameter. The black EPDM specimen was about one half the size of the others, and contained only one void in the seam. In the fabrication of the small-sized specimens, uniform pressure was applied to the newly-formed seams by placing them in a laboratory press for 4-5 seconds under about $0.50 \mathrm{MPa}\left(75 \mathrm{lbf} / \mathrm{in}^{2}\right)$. 


\section{RESULTS AND DISCUSSION}

\subsection{Large-Sized Membrane Specimens}

3.1.1. Ultrasonic Pulse Echo Method

The ultrasonic pulse echo method using the wheel transducer with water as the coupling medium was applied to the large-sized membrane specimens. All voids in the seams were detected for both the seam alone specimen and for the chamber specimen (Table 2). The seam alone specimen was placed on either a laboratory bench or on top of the EPDM membrane of the chamber specimen during the NDE evaluation.

In the tests using the wheel transducer, the echo pattern observed when the transducer was placed on bonded sections of the seam was complex and difficult to interpret because of the number of signals produced. When the wheel transducer was placed on a void, the echo pattern was also complex, but contained a unique signal that was not present in the echo pattern of the bonded area of the seam. This unique signal was used to indicate the presence of a void. The wheel transducer was rapidly scanned along the $1.2 \mathrm{~m}$ (48 in.) length of the specimen, and each of the six voids was located by the appearance of the unique signal in the echo pattern. An audio alarm, which sounded whenever the unique echo signal was produced, was also used to indicate the presence of the voids when the wheel transducer was pushed over the surface of the specimens. These results indicated that the 
use of wheel transducers may have applicability for examining long expanses of seams of roofs in service.

Unlike detecting voids using a small transducer which is manually scanned across the specimen surface, false indicators of apparent voids in bonded sections of the seam were not produced using the wheel transducer technique. The stability and mass of the rolling platform on which the transducer was mounted provided constant load and uniform contact of the transducer with the membrane specimen surface.

\subsubsection{Infrared Thermography Method}

The infrared thermography method was applied to detection of voids in the seams of the large-sized membrane specimens by using a hot air blower or heat lamps as the source of transient heat flow. During these tests, the seam alone specimen was placed on top of the chamber specimen under the heat lamps. The results of the tests are summarized in Table 2. The results indicated that, for the most part, the voids were only detected in part or not detected at all. Only void no. 2 of the chamber specimen was found to be entirely visible. These findings were in contrast with those of previous studies [1,2] and the results for smallsized specimens in the present study (see section 3.2.2) wherein voids greater than $6 \mathrm{~mm}(0.2 \mathrm{in.})$ in diameter were detected using the infrared thermography method. 
In the present study, in those cases where the volds were only detected in part, the perimeters of their geometric shapes were the main features observed in the thermographic images. The center portions of the void images displayed the same infrared image color contrast as the bonded portion of the specimen. This suggested that, during the NDE examination, transient heat flow through the center portion of the void was comparable to that occurring in the bonded sections of the seam. As a consequence, the surface temperature above the center portion of the void would not differ significantly from that above the bonded areas. A temperature differential is necessary to allow detection of the void using the infrared thermography technique. Lack of a temperature differential might be expected to occur if the two rubber sheets comprising the seam were in contact at the center portion of the void. In effect, a collapse of the incorporated void might have occurred. Figure 3 , for example, depicts two seams with voids: the first having the rubber sheets totally separated at the void, and the second having the sheets in contact at the center portion of the void.

As previously indicated, pressure was applied to the large-sized specimens during seam formation using a hand roller. It may be possible that, using the roller, the sheets of rubber at the center portion of the voids were pushed together, since the roller technique exerts pressure over a relatively small area of the specimen. The effect of pushing the rubber sheets together 
at the center portion of the voids is to create small defect areas (at the void perimeter) which are observed using the infrared thermography method (Figure 3B). It might be expected that some gap defect would be present at the perimeter of the collapsed void because of the adhesive layer at that location.

In those cases where the voids were not detected at all, it was considered that not only might the rubber sheets at the center of the voids have been in contact, but also the remaining gaps at the void perimeters were too small to be detectable using the infrared thermography method. Theoretical considerations have shown that the width of a hidden defect should be about twice the thickness of the layer covering the defect in order that it may be detected using the infrared thermography method [12]. Previous investigations at NBS have shown that a round void, $3 \mathrm{~mm}$ ( $0.13 \mathrm{in.})$ in diameter and fabricated from EPDM sheets of $1.5 \mathrm{~mm}$ ( 0.06 in.) thickness, was not detected using the infrared thermography method [2].

The possible effect of the collapsing of voids precluding their detection using the infrared thermography method was not investigated in the present study, and should be the subject of further study. Such an investigation should involve mathematical analysis to predict seam surface temperatures as a function of void configuration, and laboratory study of specimens prepared based on the results of the analysis. A question regarding the 
collapse of the voids under the load of the hand roller is why the EPOM rubber sheets did not separate after release of the roller pressure. A possible explanation is that the rubber sheets, freshly cleaned with solvent and then pushed together, developed sufficient bond at the void to be held in contact during the course of the experiment.

In considering reasons why voids in seams of the large-sized specimens were not detected using the infrared thermography method, the question was raised as to whether void thickness had an effect. To examine such a possibility, two EPDM seam specimens having uniform adhesive-layer thickness and incorporated voids were prepared. In this case, a laboratory press was used to apply pressure during bond formation. One specimen was fabricated using two-sided cellulose adhesive tape with a thickness of about $0.08 \mathrm{~mm}(0.003 \mathrm{in.})$. The second was made using two-sided EPDMseaming tape with a thickness of about $0.7 \mathrm{~mm}(0.03 \mathrm{in.})$. The thicknesses of the two specimens bracketed the range of adhesive thickness normally encountered when contact adhesives are applied to EPDM with a brush or a roller. When examined using the infrared thermography method, the voids in the two specimens were detected. It was also subjectively observed that the thicker adhesive layer provided a stronger thermal image of the voids than that given by the thin layer. 
The fact that all voids intentionally incorporated in seams were not detected in the present study using the infrared thermography method indicates that the technique may not be useful for general investigation of voids and delaminations in seams in service. Final judgment on this point should be reserved until the results of studies on the effect of void collapse are completed.

As mentioned in the introduction, an intent of preparing the chamber specimen was to investigate the possibility of using heat lamps, as simulated solar radiation, for providing the source of transient heat flow. In the laboratory test, the lamps were used to heat the membrane. When the lamps were shut off, the specimen cooled during which time the surface of the seam was scanned with the infrared camera. (Although the experiment was not conducted, it was envisioned that, in the field, cooling of a solar heated membrane might be brought about by briefly casting a shadow, e.g., using an umbrella, on the seam section under examination.) As given in Table 2, void no. 2 of the chamber specimen was detected using heat lamps as the source of transient heat flow, when unheated air was blown across the seam surface after the lamps were shut off. This result suggested that (assuming void collapse is not an issue) use of solar heating of seams on roofs as a source of transient heat flow may be practical, provided that air movement across the solar heated surface is implemented along with casting a shadow on the seam. Nevertheless, until the 
issue regarding void collapse is resolved, further investigation on solar heating as a source of transient heat flow is not considered warranted.

\subsection{Small-Sized Membrane Specimens}

\subsubsection{Ultrasonic Pulse Echo Method}

The voids in the small-sized membrane specimens (nos. 1-4) were detected using the ultrasonic pulse echo method, as given in Table 3. As was found in previous studies in this laboratory $[1,2]$, void detection was sensitive to the pressure applied to the transducer. Pressure on the transducer varied in these measurements, since the transducer was manually scanned over the surface of the membrane specimen. False indicators of the presence of voids would appear if the transducer was not kept in uniform contact with the membrane specimen surface. The CSME and the SBS-modified bitumen membrane specimens (nos. 3 \& 4 , respectively) appeared to be more sensitive to the applied pressure than the EPDM specimens. This was attributed to the non-planar nature of the surfaces. The CSME specimen was slightly embossed because of the reinforcement within the sheet. The SBS-modified bitumen was surfaced with mineral granules.

The mineral granule surfacing on the SBS-modified bitumen precluded the use of water as a transducer coupling medium for this specimen. When used as a coupling medium, the water ran between the granules and from the specimen surface with loss of 
coupling. A general purpose, petroleum-based, lubricating oil was found to be satisfactory as a coupling medium during the test. However, a general note of caution should be mentioned regarding the use of oils with roofing membrane materials. Some oils and membrane materials may not be compatible, and damage to the membrane material may result due to application of oil on the surface.

\subsubsection{Infrared Thermography Method}

The results of the NDE inspection of the small-sized membrane specimens using infrared thermography are summarized in table 3. Voids were detected in seams of the four types of membrane specimens when they were heated using the hot air blower, and also when the heated membrane specimens were cooled by blowing unheated air across the surfaces. It is noted that void collapse with the small-sized specimens might not be expected to have occurred, since pressure during seam formation was applied uniformly across the seam surface using a laboratory press.

As is given in Table 3 , the length of time during which the void image remained visible after heating ceased varied among the four types of specimens. This was presumably due to factors such as differences in adhesive thickness and in thermal properties of the membrane materials, which resulted in the various specimens achieving a uniform surface temperature at different rates. An evaluation of the thermal properties of the different membrane materials included in the study and their effect on void detection was beyond the scope of the present study. 


\section{SUMMARY AND RECOMMENDATIONS}

Investigations were made regarding the use of the ultrasonic pulse echo and the infrared thermography NDE methods for detecting voids and delaminations in adhesive-bonded seams of single-ply roofing membranes. Previous laboratory work at NBS indicated that both techniques offered the possibility for locating defects in the hidden interior portions of seams of single-ply membranes. However, further investigation was needed before the techniques would be applicable to field use.

In the present study, the principal factor investigated regarding the ultrasonic pulse echo method was the use of a wheel transducer that could possibly scan long expanses of seams quickly and at constant pressure. A wheel transducer was mounted on a rolling platform and used to detect the presence of six voids in $1.2 \mathrm{~m}$ (48 in.) long EPDM specimens. All voids were readily located as the transducer was scanned along the length of the seam, providing evidence that the ultrasonic pulse echo method using a wheel transducer can be useful as a field technique for assisting in the quality assessment of seams. False indicators of the presence of voids in bonded areas of seams were not observed during the testing with the wheel transducer. The wheel transducer was not investigated for field use.

In the case of the infrared thermography method, the primary factor investigated was the potential use of sunlight (absorbed 
solar radiation) as the source of transient heat flow in the seam. It was found that some voids incorporated intentionally in the seams were only detected in part and that other voids were not detected at all. It was postulated that collapse of the voids under the pressure applied by the roller during seam fabrication resulted in contact of the rubber sheets in the center portion of the voids. This collapse produced insufficient surface temperature differential between the bonded areas of the seam and the void areas of the seams during transient heat flow.

The present results raise concerns that the infrared thermography method may not be practical for the general detection of voids and delaminations of seams in service. It is suggested that final judgment on the utility of the infrared thermography method be reserved until the further investigations of the void collapse effect are carried out.

In the present study, the ultrasonic pulse echo and the infrared thermography methods were also applied to seam specimens fabricated from white EPDM, white chlorosulfonated polyethylene (CSME), and styrene-butadiene-styrene (SBS) modified bitumen. These tests were included since the previous studies were limited to seams fabricated from black EPDM rubber. Voids incorporated in seams of these membrane materials were detected using both NDE methods, demonstrating their potentially wide applicability to different types of elastomeric, thermoplastic, and polymer-modified bitumens. 
Based on the results of the present study, it is recommended that:

1) Investigation into the use of the ultrasonic pulse echo method be continued to study field use of wheel transducers for detecting voids in seams in service. A key item to be included should be the development of equipment for use in the field.

2) Investigation of the possible effect of void collapse on the capability of the infrared thermography method to detect hidden voids in seams be conducted. The investigation should include a mathematical analysis of seam surface temperatures as related to void configuration and laboratory testing based on the results of such analysis. 


\section{ACKNOWLEDGEMENTS}

This study was sponsored by the Naval Civil Engineering Laboratory (NCEL), Port Hueneme, California. The author expresses his appreciation to Dr. Robert Alumbaugh (NCEL) for his assistance in the development of the study, and for his support and encouragement throughout its course.

The author expresses appreciation and thanks to his NBS colleagues for their assistance in conducting the study. Mr. Dale Bentz, Mr. Edward Embree, Mr. Jessie Hairston, Mr. Jack Lee, and Mr. James Seiler contributed to the preparation of test specimens and the NDE evaluations. Special thanks are expressed to Dr. Gerald Blessing who assisted in the ultrasonic pulse echo measurements, and provided many valuable suggestions regarding the application of the method to detecting voids in seams of single-ply membranes. The assistance of Mr. Joseph Monroe, Eastern NDT (Hopewell, $\mathrm{Va}_{.}$) in providing use of the wheel transducer for the study is also acknowledged with thanks. 
1. Clifton, J.R., Pizzutti Dos Santos, J., and Rossiter, W.J., Jr., "Non-Destructive Evaluation Methods for Assessing the Quality of Seams in Single-Ply Membranes," Proceedings, 2nd International Symposium on Roofing Technology, National Roofing Contractors Association, Chicago, IL (September $1985), p p$. 433-437.

2. Rossiter, W.J., Jr. and Clifton, J.R., "The Use of Nondestructive Methods for Inspection of Single-Ply Roofing Membranes," Durability of Building Materials, in press.

3. Clifton, J.R., Carino, N.J., and Howdyshell, P., "In-Place Nondestructive Evaluation Methods for Quality Assurance of Building Materials," Technical Report M-305, Construction Engineering Research Laboratory, Champaign, IL (March 1982), 81 pages.

4. Frobel, R.K., "Methods of Constructing and Evaluating Geomembrane Seams," Vol. 2, Proceedings, International Conference on Geomembranes, Industrial Fabrics Association International, St. Paul, MN (June 1985), pp. 359-364.

5. Spanner, G.E., "Nondestructive Technique for Assessing Field Seam Quality of Prefabricated Geomebranes," Vol. 2, Proceedings, International Conference on Geomembranes, Industrial Fabrics Association International, St. Paul, MN (June 1985), pp. $369-374$.

6. Manning, D.G. and Holt, F.B., "Detecting Delaminations in Concrete Bridge Decks," Concrete International, Vol. 2, No. 11 (1980) pp. 34-41.

7. "Ultrasonic Testing," Szilard J., Ed., John Wiley \& Sons, New York (1982).

8. Dom, B.E., Evans, H.E., and Torres, D.M., "Thermographic Detection of Polymer/Metal Adhesion Failures," in "Adhesion Aspects of Polymeric Coatings," Mittal, K.L., Ed., Plenum Press, New York (1983), pp. 597-621.

9. McKnight, M.E. and Martin, J.W., "Quantitative Evaluation of Blistering and Corrosion in Organic Coating Systems," in "New Concepts for Coating Protection of Steel Structures," ASTM STP 841, Berger, D.M. and Wint, R.F., Eds., American Society for Testing and Materials, Philadelphia, PA (1984), pp. 13-20.

10. Reynolds, W.N. and Wells, G.M., "Video-Compatible Thermography," British Journal of NDT (January 1984), pp. 40-44. 
11. Sayers, C.M., "Detectability of Defects by Thermal NonDestructive Testing," British Journal of NDT (January 1984), pp. $28-33$.

12. Dom et al., op. cit., p. 616. 
Table 1. Membrane Materials Included in the Study

\begin{tabular}{|c|c|c|c|}
\hline No. & Type & $\begin{array}{l}\text { Thickness } \\
\text { mm } \\
(\text { in.) }\end{array}$ & Comment \\
\hline 1 & Black EPDM & $\begin{array}{l}1.5 \\
(0.06)\end{array}$ & $\begin{array}{l}\text { Non-reinforced; smooth } \\
\text { surfaced }\end{array}$ \\
\hline 2 & White EPDM & $\left(\begin{array}{l}1.3 \\
(0.05)\end{array}\right.$ & $\begin{array}{l}\text { Non-reinforced; smooth } \\
\text { surfaced }\end{array}$ \\
\hline 3 & White CSME $^{2}$ & $\left(\begin{array}{l}1.0 \\
(0.04)\end{array}\right.$ & $\begin{array}{l}\text { Reinforced; surface is } \\
\text { not smooth but slightly } \\
\text { embossed }\end{array}$ \\
\hline 4 & $\begin{array}{l}\text { SBS-Modjified } \\
\text { Bitumen }\end{array}$ & $\begin{array}{l}4.6 \\
(0.18)\end{array}$ & $\begin{array}{l}\text { Surfaced with white } \\
\text { granules; surface is not } \\
\text { smooth }\end{array}$ \\
\hline
\end{tabular}

1. EPDM indicates ethylene propylene diene terpolymer.

2. CSME indicates chlorosulfonated polyethylene.

3. SBS indicates styrene-butadiene-styrene. 
Table 2. Results of NDE Inspections of Large-Sized Membrane Specimens

Results

Specimen Uitrasonic

Type Pulse Echo

Wheel

Coupling

$\begin{array}{ll}\text { Seam } & \text { voids detected } \\ \text { Alone } & \text { with whel } \\ & \text { transducer using } \\ & \text { water as the } \\ & \text { coupling aedium. }\end{array}$
- During heating, the voids were only partially detected; the aatin feature observed was perineter of the volds.

- During cooling, the voids vere only partially detected: the alin feature observed was periater of the volds.

\section{Infrared Thermography}

Hot Air Blower ${ }^{1}$ Heat Lamps ${ }^{1}$
- No air blown over cooling specienen: aost volds were not detected; votd no. 6 produced an iange which apeared square and not rectangular.

- Unheated air blown over cooling specimen: soae volds vere partially detected, priaarily their periater shape: vold nos. 1 \& 2 were not detected.

\section{Chamber Specimen}
- Most voids not detected during heating; only vold no. 2 was clearly vistble; the outline of the periaeter of vold no. 4 was partially observed.

- Mo afr blown over cooling speciaen: vodds not detected.

- Unheated air blown over cooling spectaen: wost volds not detected; only votd no. 2 was clearly visible; the outline of the periaeter of vold no. 4 was partially observed.

1. This was the method by which transient heat flow was induced in the specimen. 
Table 3. Results of NDE Inspections of Small-Sized Membrane Specimens Results

Membrane

Type

$\frac{\text { Ultrasonic Pulse Echo }}{\text { Direct Transducer }} \frac{\text { Infrared Thermography }}{\text { Hot Air Blower }}$

contact

B lack

EPDM

- Void detected.

- Void detection was sensitive to the pressure applied to the transducer.

White

EPDM

- Voids detected.

- Void detection was sensitive to the pressure applied to the transducer.

White

CSME

- Voids detected.

- Void detection appeared to be more sensitive to pressure than in the case of EPDM.
- Vold was clearly visible while heating specimen with hot air.

- After heating stopped, vold inage faded in $15-20 \mathrm{~s}$.

- Membrane was heated until underside was about $50{ }^{\circ} \mathrm{C}\left(122^{\circ} \mathrm{F}\right)$, then unheated air was blown over the surface: void was visible; image faded in about 15-20 s.

- Voids were elearly visible while heating specimen with hot air.

- After heating stopped, void images remained visible for over 1 min.

- Membrane was heated until underside was about $50{ }^{\circ} \mathrm{C}\left(122^{\circ} \mathrm{F}\right)$, then unheated air was blown over the surface; voids were visible; inages remained visible for over 1 min.

- Voids were clearly visible while heating specimen with hot air.

- After heating stopped, void images remained visible for about 1 in.

- Membrane was heated until underside was about $50^{\circ} \mathrm{C}\left(122^{\circ} \mathrm{F}\right)$, then unheated air was blown over the surface: voids were visible but contrast was weak: images remained visible for about 1 min.

- Voids were clearly visible while heating specimen with hot air: inages were very sharp.

- After heating stopped, void lmages remained visiole for over 3 min.

- Membrane was heated until underside was about $45^{\circ} \mathrm{C}\left(113^{\circ} \mathrm{F}\right)$, then unheated afr was blown over the surface; voids were clearly visible; inages remained vistble for over 3 min. 


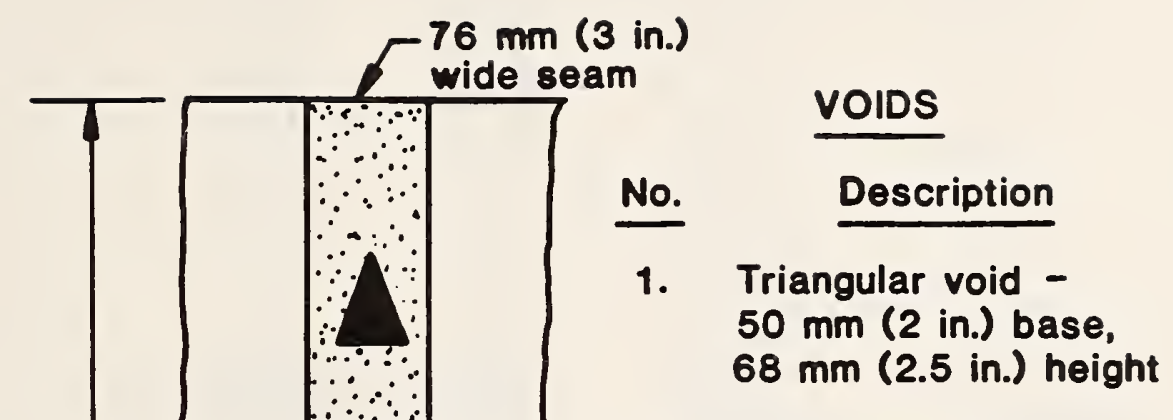

2. Rectangular void $50 \times 25 \mathrm{~mm}(2 \times 1 \mathrm{in.})$

3. Rectangular void $25 \times 50 \mathrm{~mm}(1 \times 2 \mathrm{in}$.

4. Circular void $50 \mathrm{~mm}(2 \mathrm{in}$.$) in diameter$

5. Circular void $25 \mathrm{~mm}$ ( 1 in.) in diameter

6. Rectangular void $25 \times 150 \mathrm{~mm}(2 \times 6$ in.)

Figure 1. Diagram of the $1.2 \mathrm{~m}$ ( $48 \mathrm{in.)}$ Large-Sized Test Specimen Indicating the Voids Incorporated in the Seam. 


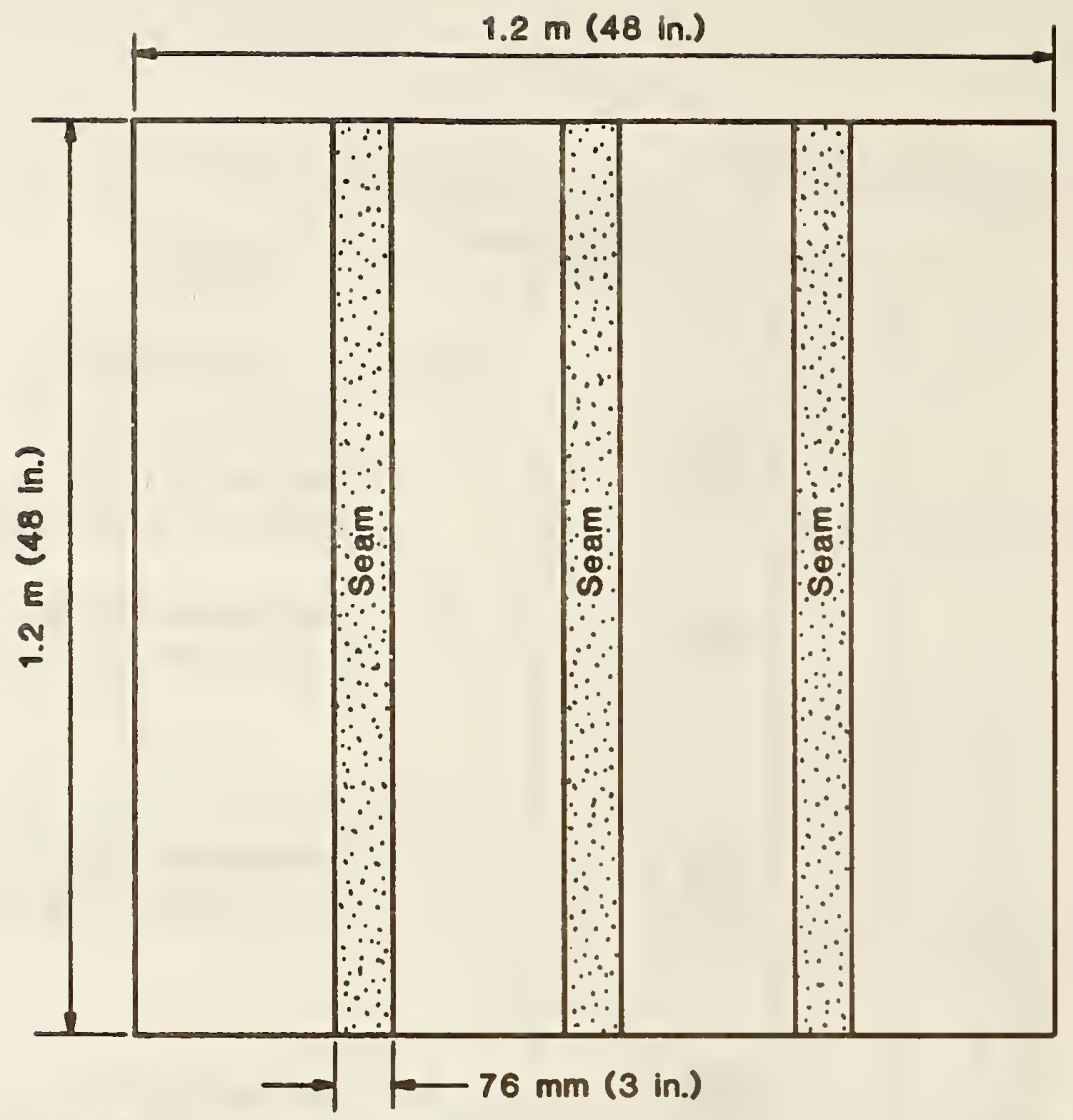

A. TOP VIEW: Seams were equidistantly spaced across the specimen

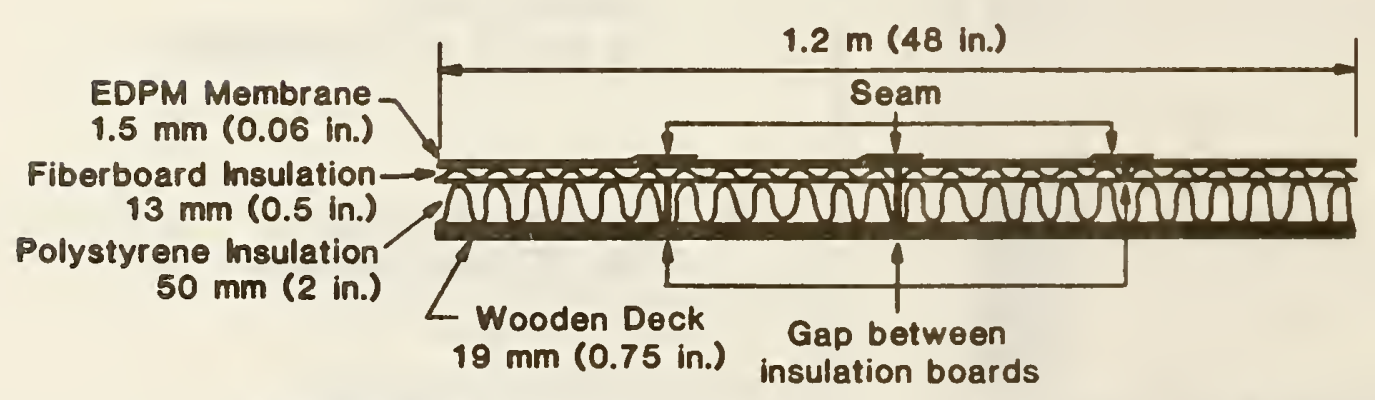

B. SIDE VIEW: Seams were located above gaps between insulation boards

Figure 2. Plan of the Chamber Test Specimen. 


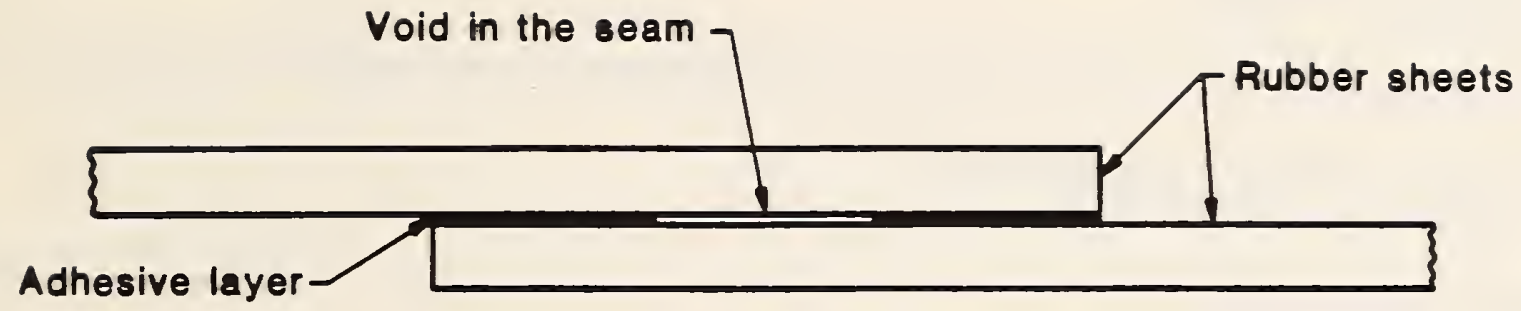

A. Lap seam with void - Rubber sheets totally separated at the void area

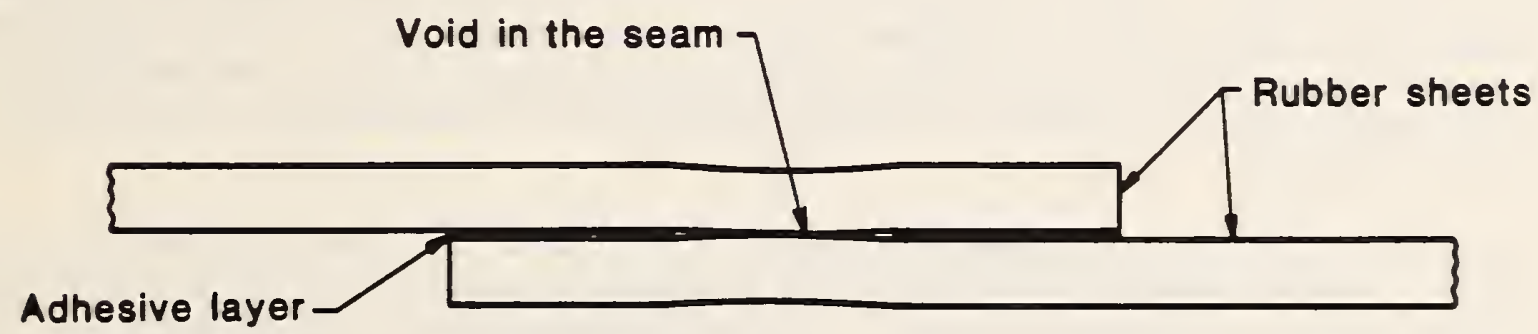

B. Lap seam with void - Rubber sheets in contact at the center portion of the void

Figure 3. Types of Voids in Lap Seams. 
BIBLIOGRAPHIC DATA

SHEET (See Instructions)

4. TITLE AND SUBTITLE

Investigation of the Use of Nondestructive Methods for Inspection of Seams of Single-Ply Roofing Membranes

\section{AUTHOR(S)}

Walter J. Rossiter, Jr.

6. PERFORMING ORGANIZATION (If joint or other than NBS, see instructions)

NATIONAL BUREAU OF STANDARDS

DEPARTMENT OF COMMERCE

WASHINGTON, D.C. 20234

9. SPONSORING ORGANIZATION NAME AND COMPLETE ADDRESS (Street, City, State, ZIP)

Naval Civil Engineering Laboratory

Port Hueneme, CA 93043-5003

10. SUPPLEMENTARY NOTES

[] Document describes a computer program; SF-185, FIPS Software Summary, is attached.

11. ABSTRACT (A 200-word or less factual summary of most significant information. If document includes a slgnificant bibliogrophy or literature survey, mention it here)

Investigations were conducted regarding the use of the ultrasonic pulse echo and the Infrared thermography nondestructive evaluation (NDE) methods for detecting volds and delaminations in adhesive-bonded seams of single-ply roofing membranes. Previous studies had indicated that these defects could be detected using the two NDE methods. In the present study, volds incorporated $1 \mathrm{n} 1.2 \mathrm{~m}$ (48 in.) $10 \mathrm{gg}$ seam test specimens were located by the pulse-echo method using a wheel transducer to scan along the length of the seam. These results indicated that the ultrasonic pulse echo method using a wheel transducer can be useful as a fleld technique for assisting in the quality assessment of seams.

When using the infrared thermography method to evaluate the seam specimens, $1 t$ was found that, unlike previous studies, only sectlons of some volds were detected and that other volds were not detected at all. It was suggested that collapse of the volds due to the applied pressure during seam formation might have provided insufficient surface temperature differential between the bonded areas of the seam and the vold areas of the seams during transient heat flow. The results ralsed concerns that the 1nfrared thermography method may not be practical for the general detection of volds of seams $1 n$ service.

12. KEY WORDS (Six to twelve entries; alphabetical order; capitalize only proper names; and separate key words by semicolons) adhesive bonds; detection; infrared thermography; membranes; nondestruct1ve evaluation; roofing; seams; single-ply; ultrasonic pulse echo; volds

\section{AVAILABILITY}

[X] Unlimited

For Official Distribution. Do Not Release to NTIS

- Order From Superintendent of Documents, U.S. Government Printing Office, Washington, D.C. 20402.

14. NO. OF PRINTED PAGES 35

15. Price

$[\mathrm{X}$. Order From National Technical Information Service (NTIS), Springfield, VA. 22161 

